Marquette University

e-Publications@Marquette

\title{
Brief Report: Does Gender Matter in Intervention for ASD? \\ Examining the Impact of the PEERS $®$ Social Skills Intervention on Social Behavior Among Females with ASD
}

\author{
Alana J. McVey \\ Marquette University \\ Hillary Schiltz \\ Marquette University \\ Angela Haendel \\ Marquette University \\ Bridget Kathleen Dolan \\ Marquette University, bridget.dolan@marquette.edu \\ Kirsten S. Willar \\ Marquette University \\ See next page for additional authors \\ Follow this and additional works at: https://epublications.marquette.edu/psych_fac \\ Part of the Psychology Commons

\section{Recommended Citation} \\ McVey, Alana J.; Schiltz, Hillary; Haendel, Angela; Dolan, Bridget Kathleen; Willar, Kirsten S.; Pleiss, Sheryl; \\ Karst, Jeffrey S.; Carson, Audrey M.; Caiozzo, Christina; Vogt, Elisabeth M.; and Van Hecke, Amy V., "Brief \\ Report: Does Gender Matter in Intervention for ASD? Examining the Impact of the PEERS $\circledast$ Social Skills \\ Intervention on Social Behavior Among Females with ASD" (2017). Psychology Faculty Research and \\ Publications. 344. \\ https://epublications.marquette.edu/psych_fac/344
}




\section{Authors}

Alana J. McVey, Hillary Schiltz, Angela Haendel, Bridget Kathleen Dolan, Kirsten S. Willar, Sheryl Pleiss, Jeffrey S. Karst, Audrey M. Carson, Christina Caiozzo, Elisabeth M. Vogt, and Amy V. Van Hecke 
Marquette University

e-Publications@Marquette

\title{
Psychology Faculty Research and Publications/College of Arts and Sciences
}

This paper is NOT THE PUBLISHED VERSION; but the author's final, peer-reviewed manuscript. The published version may be accessed by following the link in th citation below.

Journal of Autism and Developmental Disorders, Vol. 47, No. 7 (July 2017): 2282-2289. DOI. This article is (C) Springer Nature and permission has been granted for this version to appear in e-

Publications@Marquette. Springer Nature does not grant permission for this article to be further copied/distributed or hosted elsewhere without the express permission from Springer Nature.

\section{Brief Report: Does Gender Matter in Intervention for ASD? Examining the Impact of the PEERS ${ }^{\circ}$ Social Skills Intervention on Social Behavior Among Females with ASD}

\author{
Alana J. McVey \\ Department of Psychology, Marquette University, Milwaukee. WI \\ Hillary Schiltz \\ Department of Psychology, Marquette University, Milwaukee. WI \\ Angela Haendel \\ Department of Psychology, Marquette University, Milwaukee. WI \\ Bridget K. Dolan \\ Department of Psychology, Marquette University, Milwaukee. WI \\ Kirsten S. Willar \\ Department of Psychology, Marquette University, Milwaukee. WI \\ Children's Hospital Colorado, Aurora, CO
}




\section{Sheryl Pleiss}

Children's Hospital Colorado, Aurora, CO

University of Minnesota, Minneapolis, MN

\section{Jeffrey S. Karst}

Department of Psychology, Marquette University, Milwaukee. WI

Children's Hospital of Wisconsin, Milwaukee, WI

\section{Audrey M. Carson}

Department of Psychology, Marquette University, Milwaukee. WI

Texas Children's Hospital, Houston, TX

\section{Christina Caiozzo}

Department of Psychology, Marquette University, Milwaukee. WI

\section{Elisabeth Voght}

Department of Psychology, Marquette University, Milwaukee. WI

\section{Amy Vaughan Van Hecke}

Department of Psychology, Marquette University, Milwaukee. WI

\section{Abstract}

A paucity of research has been conducted to examine the effect of social skills intervention on females with ASD. Females with ASD may have more difficulty developing meaningful friendships than males, as the social climate can be more complex (Archer, Coyne, Personality and Social Psychology Review 9(3):212$230,2005)$. This study examined whether treatment response among females differed from males. One hundred and seventy-seven adolescents and young adults with ASD $(N=177)$ participated in this study. When analyzed by group, no significant differences by gender emerged: PEERS ${ }^{\circ}$ nowledge (TASSK/TYASSK, $p=.494$ ), direct interactions (QSQ, $p=.762$ ), or social responsiveness (SRS, $p=.689$; SSIS-RS, $p=.482$ ). Thus, females and males with ASD respond similarly to the PEERS intervention.

\section{Keywords}

Autism ASD Females Intervention Social skills

\section{Introduction}

Autism spectrum disorder (ASD) is characterized by challenges with social interaction and communication, as well as repetitive or restricted behaviors or interests (American Psychiatric Association 2013). Although males are more commonly diagnosed than females (with a ratio of about 4.5:1; CDC 2016), recent research has begun to turn its attention to the presentation of ASD in females 1 (Bargiela et al. 2016; Frazier et al. 2014; Halladay et al. 2015; Kreiser and White 2014; Rubenstein et al. 2015). However, a paucity of research has been conducted to examine the effect of social skills interventions on females with ASD. Broadly, literature on social skills interventions for this population has focused on males alone or males and females in aggregate (Chan et al. 2009). To better understand potential gender differences, the current study examined whether males and females with ASD differed significantly in response to a well-validated social skills intervention.

\section{ASD Diagnosis in Females}

Females are diagnosed with ASD much less frequently than males. Research to date has speculated that this discrepancy in diagnosis may be a result of differing symptom presentations among females compared to males, such as higher levels of internalizing symptoms, less self-injury, and fewer repetitive behaviors (Kreiser and 
White 2014; Mandy et al. 2012). Additionally, females may exhibit less challenging behavior in schools or at home, and thus, may be less likely to be referred for and/or receive proper psychological assessment (Kreiser and White 2014). Recent research shows that parents are less likely to raise concerns about a daughter's social behavior compared to a son's (Little et al. 2016). Further, girls and women with ASD may be better able to "camouflage" their social behavior and/or are missed by professionals altogether (Bargiela et al. 2016). Such masking of social ability among females with ASD may be due to the differences in gender socialization for girls compared to boys (Bussey and Bandura 1999). That is, girls typically engage in play with fewer peers at a time and these groups may be more selective, rewarding appropriate behavior by encouraging continued play and discouraging unwanted behavior by excluding someone from their group (Lamb et al. 1980). Females with ASD, then, may learn more appropriate social skills than boys from a young age, perhaps by experiencing greater social rejection (Kreiser and White 2014).

\section{Social Behavior Among Females with ASD}

Research on gender shows that typically developing females are encouraged by society to display more social behavior than males, for instance, spending leisure time interacting with friends (Bruyn and Cillessen 2008). In considering social functioning among females with ASD, the research findings are mixed. Some studies have found that females spend more time socializing with peers (Kuo et al. 2013), are more likely to use mimicking behavior in social situations (Hiller et al. 2016), and score higher on measures of friendship quality (Head et al. 2014) compared to males with the disorder. However, the majority of literature on the phenotypic expression, based on gender, shows that females with ASD often have more social impairments than males, and find it more difficult to be friends with neurotypical females (Bargiela et al. 2016). Frazier et al. (2014) found, among a sample of 2418 individuals with ASD (304 female) that females showed more impaired social and communication abilities on the Autism Diagnostic Observation Scale (ADOS) and Social Responsiveness Scale (SRS; two commonly used and well-validated measures of autism severity). Solomon et al. (2012) found that females with ASD showed more internalizing symptoms than males, but demonstrated no differences in terms of autism symptoms. Kreiser and White (2014), in their review, acknowledged that many tools developed to assess for ASD (including the ADOS) were validated using predominantly male samples, which may skew an assessment's sensitivity to ASD symptoms among females. Further, because fewer females may be referred for assessment than males (Kreiser and White 2014), it is possible that the females who do receive a diagnosis are the most impaired. That is, females may need to demonstrate a greater severity of symptoms in order to receive a diagnosis of ASD (Dworzynski et al. 2012).

\section{Social Functioning in Adolescence and Young Adulthood}

Adolescence is a particularly significant and complex time for development. Social relationships become more important and increasingly challenging to navigate. Research shows that typically developing adolescent females are more likely to use relational aggression, such as manipulation, rumor spreading, and social exclusion, than males (see Archer 2004; Archer and Coyne 2005; Crick and Grotpeter 1995, for reviews). Therefore, females with ASD may be particularly prone to difficulties in friendship development and maintenance with typically developing females during the adolescent years, due to challenges in understanding nuances of social interaction, such as relational aggression. Additionally, adolescent females with ASD may be more inclined to withdraw from interaction, due to negative experiences with peers and a fear of further social rejection (Bellini 2006). This pattern likely results in greater isolation among females with ASD that extends into young adulthood and beyond. Young adulthood represents a time of continued social development and maintenance of friendships, romantic relationships, and career-related social interaction that is often difficult for individuals with ASD to navigate (McVey et al. 2016). Nonetheless, while research demonstrates that females with ASD present with social skills challenges, whether to a greater or lesser extent than males, it remains unknown how females with ASD respond to social skills intervention, compared to males. 


\section{Social Skills Interventions}

There are a number of viable social skills interventions currently available for adolescents with ASD (see White et al. 2007, for a review), and a few for young adults (see Palmen et al. 2012, for a review). However, evidence for these interventions does not parse apart potential differences in response based on gender. The vast majority of studies have examined males alone or males and females in aggregate (Chan et al. 2009). One recent study measured the effect of a social skills program developed specifically for adolescent females with ASD, targeting social behaviors related to the norms for the neurotypical adolescent females, such as reciprocal conversation, with the goals of bolstering empowerment and self-confidence (Jamison and Schuttler 2017). The study, however, did not address differences in response to intervention based on gender, since males were not included. The single study identified by the authors that examined gender differences found that females with ASD who underwent intervention spent more time participating in a group interaction with peers than did males with ASD, who spent more time alone (McMahon et al. 2012). The researchers did not, however, address gender differences in response to the intervention itself.

Although research demonstrates that a number of social skills interventions are efficacious, one intervention in particular, the Program for the Education and Enrichment of Relational Skills (PEERS ${ }^{\circ}$ ), has been well-validated by multiple sites (Laugeson et al. 2012; Schohl et al. 2014; Yoo et al. 2014) and addresses relational aggression directly. The developers have recently published a young adult version, PEERS ${ }^{\circ}$ for Young Adults, which has been found to be efficacious as well (Gantman et al. 2012; Laugeson et al. 2015; McVey et al. 2016).

\section{Aims of the Current Study}

The primary aim of the current study was to examine if changes in social behavior among female adolescents and young adults with ASD differed from males who underwent the same social skills intervention. Potential differences in the presentation of social difficulties for females with ASD compared to males with ASD prior to intervention were also explored.

\section{Method}

\section{Participants}

Two-hundred and fifty participants were recruited for the present study. Participants were male and female adolescents and young adults with high-functioning ASD, recruited from local intervention agencies, community support groups, and an in-house waiting list at an Autism Clinic at a private midwestern university. Existing relationships with these organizations facilitated recruitment, and Institutional Review Board (IRB) approval was obtained prior to advertisements and data collection (McVey et al. 2016, 2014). Informed consent was obtained from all individual participants included in the study. Please see Schohl et al. (2014) and McVey et al. (2016) for details on recruitment, exclusionary criteria, and random assignment. Parents or primary caregivers for the adolescents completed a demographic form that asked them to report the gender of their adolescent; young adults completed a complementary form that asked them to report their own gender. This report was used to classify the participants as male or female. Likely, reported gender for this sample corresponds with the biological sex of the participant, however this question was not directly asked. The final sample was comprised of 177 participants ( 27 female). Figure 1 shows a CONSORT diagram of participant involvement and completion status. 


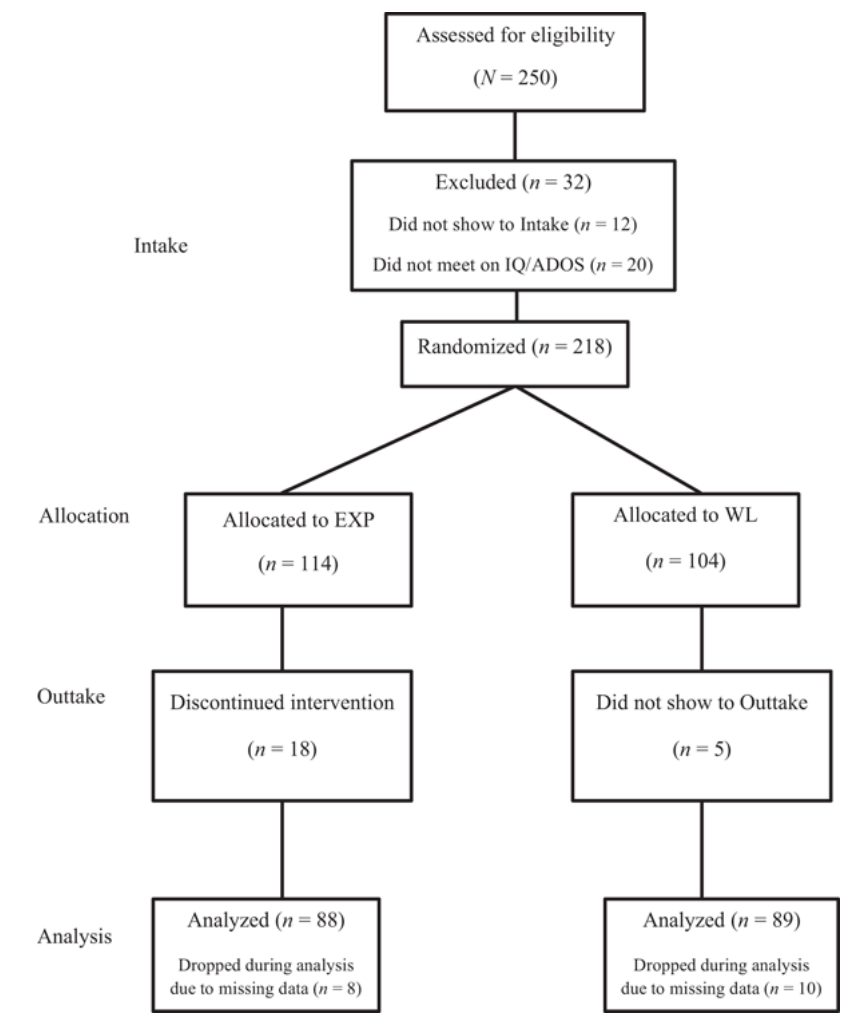

Fig. 1 CONSORT recruitment diagram

\section{PEERS ${ }^{\circledast}$ Intervention}

The PEERS ${ }^{\circ}$ and PEERS ${ }^{\circ}$ for Young Adults interventions were administered as described by the developers, utilizing the respective manuals (Laugeson in press; Laugeson and Frankel 2011). Both interventions utilize didactic, role plays, behavioral rehearsals, and homework assignments to provide the adolescents and young adults with several opportunities to engage in the social skills taught by PEERS ${ }^{\circ}$ (Laugeson et al. 2012, 2015). Regarding the content, both interventions focus heavily on bolstering conversational skills, including etiquette for conversations with one other person and groups of people, electronic communication, and resolving disagreements. Other important topics include employment of perspective-taking skills, such as monitoring how others respond to humor, etiquette for games and sports, and responding to teasing and bullying. In addition, the PEERS ${ }^{\circ}$ for Young Adultsintervention includes four modules pertaining to dating etiquette, which include expressing romantic interest, the steps leading up to and including a date, and general guidelines for dating. Further description of the administration of the interventions can be found in Schohl et al. (2014) for PEERS ${ }^{\circ}$ and McVey et al. (2016) for PEERS ${ }^{\circ}$ for Young Adults. Session content of the interventions can be found in Table $\underline{1}$ for PEERS ${ }^{\circ}$ and Table $\underline{2}$ for PEERS ${ }^{\circ}$ for Young Adults.

Table 1. PEERS ${ }^{\bullet}$ sessions and associated content

\begin{tabular}{|l|l|}
\hline Session didactic & \\
\hline 1 & Introduction and conversational skills I: trading information \\
\hline 2 & Conversational skills II: two-way conversations \\
\hline 3 & Conversational skills III: electronic communication \\
\hline 4 & Choosing appropriate friends \\
\hline 5 & Appropriate use of humor \\
\hline
\end{tabular}




\begin{tabular}{|l|l|}
\hline 6 & Peer entry I: entering a conversation \\
\hline 7 & Peer entry II: exiting a conversation \\
\hline 8 & Get-togethers \\
\hline 9 & Good sportsmanship \\
\hline 10 & Rejection I: teasing and embarrassing feedback \\
\hline 11 & Rejection II: bullying and bad reputations \\
\hline 12 & Handling disagreements \\
\hline 13 & Rumors and gossip \\
\hline 14 & Graduation and termination \\
\hline
\end{tabular}

Reprinted with permission of the authors

Table 2. PEERS ${ }^{\bullet}$ for Young Adults sessions and associated content

\begin{tabular}{|l|l|}
\hline Session didactic & \\
\hline 1 & Trading information and starting conversations \\
\hline 3 & Trading information and maintaining conversations \\
\hline 4 & Finding a source of friends \\
\hline 5 & Electronic communication \\
\hline 6 & Appropriate use of humor \\
\hline 8 & Entering group conversations \\
\hline 9 & Exiting conversations \\
\hline 10 & Get-togethers \\
\hline 11 & Dating etiquette I: letting someone know you like them \\
\hline 12 & Dating etiquette II: asking someone on a date \\
\hline 13 & Dating etiquette III: going on dates \\
\hline 14 & Dating etiquette IV: dating do's and don't \\
\hline 15 & Handling disagreements \\
\hline 16 & Handling direct bullying \\
\hline Hepring & Handling indirect bullying \\
\hline
\end{tabular}

Reprinted with permission of the authors

\section{Measures}

Participants and their parent/primary caregiver completed a battery of social behavior questionnaires at preand post-intervention. Specifically, participants completed the Test of Adolescent Social Skills Knowledge (TASSK; Laugeson et al. 2009) or Test of Young Adult Social Skills Knowledge (TYASSK; Gantman et al. 2012), which assess for PEERS ${ }^{\circ}$ knowledge. Internal consistency was 0.45 for the TASSK and 0.44 for the TYASSK, which is consistent with previous findings, and was expected as the measures were not created to capture any one particular construct. Parents or primary caregivers completed the Social Responsiveness Scale (SRS; Constantino et al. 2003), which is a measure of autism-related behaviors, and the Social Skills Improvement System - Rating 
Scales (SSIS-RS; Gresham and Elliott 2008), which assesses improvements in social skills. The SRS is comprised of five subscales: Social Awareness, Social Cognition, Social Communication, Social Motivation, and Restricted Interests and Repetitive Behavior; the total score was used here. The SSIS-RS has two subscales: Social Skills and Competing Problem Behaviors; the Social Skills subscale was used here. Internal consistency for the SRS was 0.92 and for the SSIS-RS was 0.75. The Quality of Socialization Questionnaire (Gantman et al. 2012; Laugeson et al. 2009) was completed by the parent or primary caregivers for the adolescents and by the participants themselves for the young adults. The QSQ asks how many get-togethers the participant has hosted and been invited to over the past month. Internal consistency was not evaluated here, consistent with previous studies (Gantman et al. 2012; Laugeson et al. 2009). Taken together, the TASSK/TYASSK, SRS, and SSIS-RS are used to assess responder versus non-responder status for the PEERS intervention. Specifically, significant improvement in two out of three of these measures indicates a positive response to treatment (L. Laugeson, personal communication 2016). The QSQ was included as a supplemental measure of social interaction.

\section{Results}

Statistical analyses were conducted using SPSS 23.0 (IBM Corp. 2016). The alpha level for the significance criterion was set at 0.05 for hypothesis tests. Data presented here represents an aggregate of unpublished data $(n=78)$ as well as data collected from participants previously published in both Schohl et al. (2014) and McVey et al. (2016; $n=54$ and $n=46$, respectively). Because the purpose of this study was to examine potential differences in response to intervention by gender, not to examine the efficacy of the PEERS ${ }^{\circ}$ interventions in general, the latter participants, that is, those with previously reported data, were included here for adequate statistical power. Eighteen participants ( $n=18 ; 6$ female) were excluded due to missing outcome data. Data were screened for normality, impossible values, and outliers. Four data points were found to be significant outliers and were subsequently Winsorized to the next highest value (QSQ Pre: 16 and 13, to 11; QSQ Post: 22 and 20, to 15; Tabachnick and Fidell 2013). Otherwise, data were found to be within normal limits. T-test and Chi square tests for independence were used to assess group differences for experimental (EXP) versus waitlist control (WL) and male versus female. For EXP versus $W L$, no significant differences were uncovered for age $(t(175)=1.479, p=.338$, two tailed, $95 \% \mathrm{Cl}[-0.26,1.83])$, primary parent/caregiver education $\left(\chi^{2}=8.049, p=.328\right.$, Cramer's V $\left.=0.213\right)$, race $\left(\chi^{2}=4.132, p=.531\right.$, Cramer's V $\left.=0.155\right)$, ethnicity $\left(\chi^{2}=0.104, p=.747\right.$, Cramer's V $\left.=0.025\right)$, socioeconomic status $\left(\chi^{2}=8.043, p=.090\right.$, Cramer's V $\left.=0.217\right)$, KBIT-2 FSIQ $(t(175)=1.20, p=.962$, two tailed, $95 \% \mathrm{Cl}[-2.13,8.60]$, or ADOS-G total score $(t(175)=-0.923, p=.093$, two tailed, $95 \% \mathrm{Cl}[-1.61,0.584])$. For male versus female, no significant differences were uncovered for age $(t(175)=-1.391, p=.166$, two tailed, $95 \% \mathrm{Cl}[-2.478,0.429])$, primary parent/caregiver education $\left(\chi^{2}=6.314, p=.504\right.$, Cramer's V $\left.=0.189\right)$, race $\left(\chi^{2}=2.524, p=.773\right.$, Cramer's V $\left.=0.121\right)$, ethnicity $\left(\chi^{2}=1.030, p=.310\right.$, Cramer's $\left.V=0.077\right)$, socioeconomic status $\left(\chi^{2}=3.954, p=.412\right.$, Cramer's $\left.V=0.152\right)$, KBIT-2 FSIQ $(t(175)=-0.759, p=.449$, two tailed, $95 \% \mathrm{Cl}[-10.360,4.607])$, or ADOS-G total score $(t(175)=1.221, p=.224$, two tailed, $95 \% \mathrm{Cl}[-0.581-2.465])$.

To examine potential differences by gender, independent samples $t$-tests were employed on all dependent variables at pre-test. There were no significant effects of gender in terms of self-report of social skills knowledge via the TASSK/TYASSK $(t(175)=-0.221, p=.826$, two tailed, $95 \% \mathrm{Cl}[-1.658,1.324])$ and direct social contacts via the QSQ $(t(175)=-0.498, p=.619$, two tailed, $95 \% \mathrm{Cl}[-1.339,0.799])$, as well as parent-report of autismrelated behaviors via the SRS $(t(175)=-0.147, p=.883$, two tailed, $95 \% \mathrm{Cl}[-10.720,9.230])$, and social skills via the SSIS-RS $(t(175)=1.571, p=.118$, two tailed, $95 \% \mathrm{Cl}[-1.418,12.476])$ at pre-test.

In order to determine any differences by gender in response to treatment, four repeated measures analyses of variance (ANOVAs) were run to examine Group (EXP vs. WL) by Time (Pre vs. Post) by Gender (Male vs. Female) effects. 
In terms of self-report of social skills knowledge on the TASSK/TYASSK, there was a significant main effect of Time $\left(F(1,173)=194.44, p<.001\right.$, partial $\left.\eta^{2}=0.529\right)$ which was further qualified by a significant Group*Time interaction $\left(F(1,173)=144.32, p<.001\right.$, partial $\left.\eta^{2}=0.455\right)$. However, there was no significant main effect (Gender, $F(1,173)=0.272, p=.602$, partial $\eta^{2}=0.002$ ) or interaction effect of Gender (Time*Gender, $F(1,173)=0.469, p=.494$, partial $\eta^{2}=0.003$; Time*Group*Gender, $F(1,173)=0.002, p=.965$, partial $\left.\eta^{2}<0.001\right)$.

For direct social contacts via the QSQ, there was a significant main effect of Time $(F(1,173)=15.168, p<.001$, partial $\left.\eta^{2}=0.081\right)$, which was further qualified by a significant Group*Time interaction $\left(F(1,173)=8.138, p=.005\right.$, partial $\left.\eta^{2}=0.045\right)$. However, there was no significant main effect (Gender, $F(1,173)=0.490, p=.485$, partial $\eta^{2}=0.003$ ) or interaction effect of Gender (Time*Gender, $F(1,173)=0.092, p=.762$, partial $\eta^{2}=0.001$; Time*Group*Gender, $F(1,173)=0.209, p=.648$, partial $\left.\eta^{2}=0.001\right)$.

Parent-report of autism related behaviors on the SRS, showed a significant main effect of Time $\left(F(1,173)=35.775, p<.001\right.$, partial $\left.\eta^{2}=0.171\right)$, which was further qualified by a significant Group*Time interaction $\left(F(1,173)=8.917, p=.003\right.$, partial $\left.\eta^{2}=0.049\right)$. However, there was no significant main effect (Gender, $F(1,173)=0.007, p=.935$, partial $\eta^{2}<0.001$ ) or interaction effect of Gender (Time*Gender, $F(1,173)=0.161, p=.689$, partial $\eta^{2}=0.001$; Time*Group*Gender, $F(1,173)=0.109, p=.741$, partial $\left.\eta^{2}=0.001\right)$.

Results of parent-report on social skills via the SSIS-RS demonstrated a significant main effect of Time $\left(F(1,173)=19.856, p<.001\right.$, partial $\left.\eta^{2}=0.103\right)$, which was further qualified by a significant Group*Time interaction $\left(F(1,173)=5.050, p=.026\right.$, partial $\left.\eta^{2}=0.028\right)$. However, there was no significant main effect (Gender, $F(1,173)=1.683, p=.196$, partial $\eta^{2}=0.010$ ) or interaction effect of Gender (Time*Gender, $F(1,173)=0.497, p=.482$, partial $\eta^{2}=0.003$; Time*Group*Gender, $F(1,173)=0.338, p=.562$, partial $\left.\eta^{2}=0.002\right)$.

\section{Discussion}

Results suggest that the PEERS ${ }^{\circ}$ and PEERS ${ }^{\circ}$ for Young Adultsinterventions are as efficacious for females with ASD as males. Research shows that males and females often demonstrate differing presentations of the disorder (Dean 2014), and females may be thought to be more "socialized" than males (Goldman 2013; Head et al. 2014; Solomon et al. 2012), or may exhibit more social difficulties (Bargiela et al. 2016). While the current sample showed no significant quantitative differences by gender in IQ, autism severity, or social behaviors prior to the intervention, there may have been qualitative differences in the presentation of ASD in females compared to males. However, examining qualitative differences was beyond the scope of the present study.

The current findings indicate, despite these possible differences in phenotypic presentation, that females with ASD show no differences in the pattern of improvement in social skills compared to males. While females with ASD may demonstrate more positive social behaviors prior to intervention (Kuo et al. 2013), these results indicate that females with ASD still show significant gains from intervention, and therefore should not be overlooked or otherwise excluded from these services. It remains unknown how females in a predominantly male group respond to, or think about, the intervention, compared to a group with a more even gender distribution. The use of qualitative measures could be employed to better understand the experience from the participants' perspective. Further, an all-female PEERS ${ }^{\bullet}$ group would provide an opportunity rife for examination of interpersonal engagement for this population, where third party observation, along with self-report measures, could be used to garner more information. While exploring the mechanisms of the intervention was beyond the limits of the present study, it is interesting to consider which components of PEERS may be most 
beneficial for females with ASD, based on their presentation, and whether they differ from males, or whether females may fare better (or worse) in an even gendered or all-female group. Further, exploration of potential differences in response to intervention based on biological sex versus gender is merited, along with considerations that go beyond the heteronormative binary categorization of biological sex and gender.

There were several limitations in the present study that merit mention. First, the present sample of females, relative to males, was small. This is likely a direct result of differences in diagnostic ratio for males and females, but limits the generalizability of the findings. A second limitation was the lack of a treatment as usual group. Without this, it is unknown whether the findings may be attributed to PEERS ${ }^{\bullet}$ specifically, or may represent response to social skills interventions more broadly. Finally, this study did not examine self or parent qualitative response to the intervention. Future studies could gather qualitative, as well as quantitative data, to learn more about how female participants with ASD experience the intervention.

In conclusion, the present findings provide preliminary evidence that the PEERS ${ }^{\circ}$ social skills interventions are as beneficial for females with ASD as males with the disorder.

\section{Footnotes}

1. The term female in the present paper does not differentiate female biological sex (which refers to biological differences: chromosomes, hormonal profiles, internal and external sex organs) versus female gender (which describes the characteristics that a society or culture delineates as masculine or feminine). Though a meaningful distinction certainly exists between the constructs of gender and biological sex, sufficient research regarding these constructs as pertains to social skills intervention outcome for females with ASD was not uncovered. Consistent with existing literature on the topic (Kreiser and White 2014), research presented in the present paper includes studies that classify females both by gender and by biological sex, without distinctions made between them.

\section{Notes}

\section{Acknowledgments}

The authors would like to acknowledge grant support from the Autism Society of Southeastern Wisconsin (ASSEW), Marquette University, and the National Center for Advancing Translational Sciences, National Institutes of Health, through Grant Nos. UL1TR001436 and KL2TR001438. Its contents are solely the responsibility of the authors and do not necessarily represent the official views of the NIH. The authors would like to thank the families for their participation in our research, as well as acknowledge the Marquette Autism Project undergraduate research team for their diligent work on this project. This paper was presented as a poster presentation at the International Meeting for Autism Research (IMFAR) May 2016 conference under the title: Examining the Impact of the PEERS ${ }^{\circ}$ Social Skills Intervention on Females with ASD. Finally, the authors wish to extend their gratitude to Dr. Elizabeth Laugeson, Psy.D., UCLA for her assistance in offering the PEERS ${ }^{\bullet}$ interventions in Wisconsin.

\section{Author Contributions}

AM conceived of the study, participated in its coordination, participated in delivery of the intervention, conducted the statistical analyses and interpretation of the data, and drafted the manuscript; HS assisted with statistical analyses and interpretation of the data and revised the manuscript; BD, KW, SP, JK, and AC participated in the delivery of the intervention and data acquisition; $\mathrm{AH}, \mathrm{CC}$, and $\mathrm{EV}$ participated in the delivery of the intervention; AVVH assisted in the conception, design, and coordination of the study, reviewed the 
statistical analyses and interpretation of the data, and revised the manuscript. All authors read and approved the final manuscript.

\section{Funding}

This Project was funded by the Autism Society of Southeastern Wisconsin, Marquette University, and the National Center for Advancing Translational Sciences, National Institutes of Health, through Grant Nos. UL1TR001436 and KL2TR001438. Its contents are solely the responsibility of the authors and do not necessarily represent the official views of the NIH.

\section{Compliance with Ethical Standards}

\section{Conflict of interest}

Alana McVey, Hillary Schiltz, Angela Haendel, Bridget Dolan, Kirsten Willar, Sheryl Pleiss, Jeffrey Karst, Audrey Carson, Christina Caiozzo, Elisabeth Vogt, Amy Vaughan Van Hecke declare that they have no conflicts of interest.

\section{Ethical Approval}

All procedures performed in studies involving human participants were in accordance with the ethical standards of the institutional and/or national research committee and with the 1964 Helsinki declaration and its later amendments or comparable ethical standards.

\section{Informed Consent}

Informed consent was obtained from all individual participants included in the study.

\section{References}

American Psychiatric Association. (2013). Diagnostic and statistical manual of mental disorders (5th ed). Washington, DC: American Psychiatric Association.

Archer, J. (2004). Sex differences in aggression in real-world settings: A meta-analytic review. Review of General Psychology, 8(4), 291.

Archer, J., \& Coyne, S. M. (2005). An integrated review of indirect, relational, and social aggression. Personality and Social Psychology Review, 9(3), 212-230.

Bargiela, S., Steward, R., \& Mandy, W. (2016). The experiences of late-diagnosed women with autism spectrum conditions: An investigation of the female autism phenotype. Journal of Autism and Developmental Disorders, 46(10), 3281-3294.

Bellini, S. (2006). The development of social anxiety in adolescents with autism spectrum disorders. Focus on Autism and Other Developmental Disabilities, 21(3), 138-145. doi: $10.1177 / 10883576060210030201$.

Bussey, K., \& Bandura, A. (1999). Social cognitive theory of gender development and differentiation. Psychological Review, 106(4), 676.

CDC. (2016). Facts About ASDs. Retrieved February 25, 2015, from http://www.cdc.gov/ncbddd/autism/facts.html.

Chan, J. M., Lang, R., Rispoli, M., O’Reilly, M., Sigafoos, J., \& Cole, H. (2009). Use of peer-mediated interventions in the treatment of autism spectrum disorders: a systematic review. Research in Autism Spectrum Disorders, 3(4), 876-889. 
Constantino, J. N., Davis, S. A., Todd, R. D., Schindler, M. K., Gross, M. M., Brophy, S. L., ... Reich, W. (2003). Validation of a brief quantitative measure of autistic traits: Comparison of the social responsiveness scale with the autism diagnostic interview-revised. Journal of Autism and Developmental Disorders, 33(4), 427-433. doi: 10.1023/A:1025014929212.

Crick, N. R., \& Grotpeter, J. K. (1995). Relational aggression, gender, and social-psychological adjustment. Child Development, 66, 710-722.

de Bruyn, E. H., \& Cillessen, A. H. N. (2008). Leisure activity preferences and perceived popularity in early adolescence. Journal of Leisure Research, 40(3), 442-457.

Dean, M. C. (2014). Sex differences and gendered behaviors: An analysis of school-age children and adolescents with high-functioning autism. Dissertation Abstracts International Section A: Humanities and Social Sciences, (12-A(E)), No Pagination Specified.

Dworzynski, K., Ronald, A., Bolton, P., \& Happé, F. (2012). How different are girls and boys above and below the diagnostic threshold for autism spectrum disorders? Journal of the American Academy of Child \& Adolescent Psychiatry, 51(8), 788-797.

Frazier, T. W., Georgiades, S., Bishop, S. L., \& Hardan, A. Y. (2014). Behavioral and cognitive characteristics of females and males with autism in the Simons Simplex Collection. Journal of the American Academy of Child \& Adolescent Psychiatry, 53(3), 329-340.

Gantman, A., Kapp, S. K., Orenski, K., \& Laugeson, E. A. (2012). Social skills training for young adults with high-functioning autism spectrum disorders: A randomized controlled pilot study. Journal of Autism and Developmental Disorders, 42(6), 1094-1103. doi: $10.1007 / \mathrm{s} 10803-011-1350-6$.

Goldman, S. (2013). Opinion: Sex, gender and the diagnosis of autism-A biosocial view of the male preponderance. Research in Autism Spectrum Disorders, 7(6), 675-679.

Gresham, F., \& Elliott, S. N. (2008). Social skills improvement system (SSIS) rating scales. Bloomington, $\mathrm{MN}$ : Pearson Assessments. Retrieved from http://www.strivetogether.org/sites/default/files/images/45a\%20Social\%20Skills\%20Im provement\%20System.pdf.

Halladay, A. K., Bishop, S., Constantino, J. N., Daniels, A. M., Koenig, K., Palmer, K., ... others (2015). Sex and gender differences in autism spectrum disorder: Summarizing evidence gaps and identifying emerging areas of priority. Molecular Autism, 6(1), 1.

Head, A. M., McGillivray, J. A., \& Stokes, M. A. (2014). Gender differences in emotionality and sociability in children with autism spectrum disorders. Molecular Autism, 5, 19. doi: 10.1186/2040-2392-5-19.

Hiller, R. M., Young, R. L., \& Weber, N. (2016). Sex differences in pre-diagnosis concerns for children later diagnosed with autism spectrum disorder. Autism, 20(1), 75-84. doi: $10.1177 / 1362361314568899$.

IBM Corp. (2016). IBM SPSS Statistics for Windows (Version 23.0). Armonk, NY.

Jamison, T. R., \& Schuttler, J. O. (2017). Overview and preliminary evidence for a social skills and selfcare curriculum for adolescent females with autism: The girls night out model. Journal of Autism and Developmental Disorders, 47(1), 110-125.

Kreiser, N. L., \& White, S. W. (2014). ASD in females: Are we overstating the gender difference in diagnosis? Clinical Child and Family Psychology Review, 17(1), 67-84.

Kuo, M. H., Orsmond, G. I., Cohn, E. S., \& Coster, W. J. (2013). Friendship characteristics and activity patterns of adolescents with an autism spectrum disorder. Autism, 17(4), 481-500.

doi: $10.1177 / 1362361311416380$. 
Lamb, M. E., Easterbrooks, M. A., \& Holden, G. W. (1980). Reinforcement and punishment among preschoolers: Characteristics, effects, and correlates. Child Development, 51, 1230-1236.

Laugeson, E. A., \& Frankel, F. (2011). Social skills for teenagers with developmental and autism spectrum disorders: The PEERS treatment manual. Routledge. Retrieved from https://books.google.com/books?hl=en\&lr=\&id=wsmOAgAAQBAJ\&oi=fnd\&pg=PP1\&dq= peers+manual\&ots=dOizH0j8Wk\&sig=S5WgS7-9IYOgVHtsnWmiiC xdLc.

Laugeson, E. A., Frankel, F., Gantman, A., Dillon, A. R., \& Mogil, C. (2012). Evidence-based social skills training for adolescents with autism spectrum disorders: The UCLA PEERS program. Journal of Autism and Developmental Disorders, 42(6), 1025-1036. doi: 10.1007/s10803-011-1339-1.

Laugeson, E. A., Frankel, F., Mogil, C., \& Dillon, A. R. (2009). Parent-assisted social skills training to improve friendships in teens with autism spectrum disorders. Journal of Autism and Developmental Disorders, 39(4), 596-606. doi: 10.1007/s10803-008-0664-5.

Laugeson, E. A., Gantman, A., Kapp, S. K., Orenski, K., \& Ellingsen, R. (2015). A randomized controlled trial to improve social skills in young adults with autism spectrum disorder: The UCLA PEERS ${ }^{\oplus}$ program. Journal of Autism and Developmental Disorders, 45(12), 3978-3989. doi: 10.1007/s10803-015-2504-8.

Laugeson, E. A. (in press). The PEERS treatment manual for young adults with autism spectrum disorder: Evidence-based social skills training. New York, NY: Routledge.

Little, L. M., Wallisch, A., Salley, B., \& Jamison, R. (2016). Do early caregiver concerns differ for girls with autism spectrum disorders? Autism. doi: 10.1177/1362361316664188.

Mandy, W., Chilvers, R., Chowdhury, U., Salter, G., Seigal, A., \& Skuse, D. (2012). Sex differences in autism spectrum disorder: Evidence from a large sample of children and adolescents. Journal of Autism and Developmental Disorders, 42(7), 1304-1313. doi: 10.1007/s10803-011-1356-0.

McMahon, C. M., Vismara, L. A., \& Solomon, M. (2012). Measuring changes in social behavior during a social skills intervention for higher-functioning children and adolescents with autism spectrum disorder. Journal of Autism and Developmental Disorders, 43(8), 1843-1856. doi: $10.1007 / \mathrm{s} 10803-012-1733-3$.

McVey, A. J., Dolan, B. K., Willar, K. S., Pleiss, S., Karst, J. S., Casnar, C. L., ... \& Van Hecke, A. V. (2016). A replication and extension of the PEERS ${ }^{\oplus}$ for young adults social skills intervention: Examining effects on social skills and social anxiety in young adults with autism spectrum disorder. Journal of Autism and Developmental Disorders, 46(12), 3739-3754. doi: 10.1007/s10803-016-2911-5.

Palmen, A., Didden, R., \& Lang, R. (2012). A systematic review of behavioral intervention research on adaptive skill building in high-functioning young adults with autism spectrum disorder. Research in Autism Spectrum Disorders, 6(2), 602-617. doi: 10.1016/j.rasd.2011.10.001.

Rubenstein, E., Wiggins, L. D., \& Lee, L.-C. (2015). A review of the differences in developmental, psychiatric, and medical endophenotypes between males and females with autism spectrum disorder. Journal of Developmental and Physical Disabilities, 27(1), 119-139.

Schohl, K. A., Van Hecke, A. V., Carson, A. M.,Dolan, B., Karst, J., \& Stevens, S. (2014). A replication and extension of the PEERS intervention: Examining effects on social skills and social anxiety in adolescents with autism spectrum disorders. Journal of Autism and Developmental Disorders, 44(3), 532-545. doi: 10.1007/s10803-013-1900-1.

Solomon, M., Miller, M., Taylor, S. L., Hinshaw, S. P., \& Carter, C. S. (2012). Autism symptoms and internalizing psychopathology in girls and boys with autism spectrum disorders. Journal of Autism and Developmental Disorders, 42, 48-59. 
Tabachnick, B. G., \& Fidell, L. S. (2013). Using multivariate statistics. Retrieved from https://www.ulb.tu-darmstadt.de/tocs/135813948.pdf.

White, S. W., Keonig, K., \& Scahill, L. (2007). Social skills development in children with autism spectrum disorders: A review of the intervention research. Journal of Autism and Developmental Disorders, 37(10), 1858-1868. doi: 10.1007/s10803-006-0320-x.

Yoo, H.-J., Bahn, G., Cho, I.-H., Kim, E.-K., Kim, J.-H., Min, J.-W., ... others. (2014). A randomized controlled trial of the Korean version of the PEERS ${ }^{\circledast}$ parent-assisted social skills training program for teens with ASD. Autism Research, 7(1), 145-161. doi: 10.1002/aur.1354. 